\title{
Electrical Oxygen-compressed Cold Application Cuff on Pain among Patients with Musculoskeletal Disorders
}

\author{
Malarmathi $\mathrm{M}^{1}$, Renuka $\mathrm{K}^{2}$
}

\begin{abstract}
In this article, pain due to musculoskeletal disorders is often regularly ignored by the general public; however, it is one of the most significant reasons for weight to the general public as far as incapacity around the world. The present investigation is meant to evaluate the degree of torment in musculoskeletal issue through evidence-based research. Cold and compression are routinely applied or immediately after acute injury to help in relieving pain, and it will reduce swelling and speed functional recovery. Literature review is to describe the published clinical findings regarding combined cold and compression therapy in the management of pain in musculoskeletal disorders. Cold compression therapy provides better outcomes such as pain relief compared to alternative interventions. The efficacy of oxygen-compressed cold application in pain reduction in patients with musculoskeletal disorders was also studied. These observations have resulted in technological advances directed toward combining these modalities in an effort to effectively manage and prevent musculoskeletal injury and disorders. In this review, the scientific basis for thermal-based therapeutic modalities, both alone and in conjunction with soft-tissue massage and compression, will be discussed. Additionally, the advantages of the effective device for the treatment and prevention of pain among patients with musculoskeletal disorders will be considered.
\end{abstract}

Keywords: Cold application, Musculoskeletal disorders, Oxygen-compressed cold application.

Pondicherry Journal of Nursing (2019): 10.5005/jp-journals-10084-12123

\section{INTRODUCTION}

Musculoskeletal conditions such as muscles, bones, joints, and related tissues, for example, ligaments and tendons include in excess of 150 disorders that influence the locomotor framework, are extensively placed into musculoskeletal disorders. ${ }^{1}$ Musculoskeletal issues are one of the significant reasons for morbidity. ${ }^{2}$ The second most basic reason for handicap around the world, estimated by years lived with incapacity, is that almost all of them suffer back pain, which has become the most incessant condition. ${ }^{3}$ The worldwide commonness of MSDs ranges from $14 \%$ to as high as $42 \%$; then again in India, epidemiological examinations show the networkbased pervasiveness of about $20 \%$. As of now, over $12 \%$ of the World's older population lives in India. ${ }^{4}$ Musculoskeletal ailments and torment can happen from a solitary or aggregate injury and cause torment or tangible unsettling influences in different areas of the body like the back, neck, or shoulders. They can grow either as intense or as constant conditions- the last are normal, speaking to $30-40 \%$ of all ceaseless diseases. ${ }^{5}$ Analysis of information from World Health Organization's study on worldwide old age and adult people states that the point to the high significance among joint pain in low- and middle-class income people, especially among those in a lower financial position. ${ }^{6}$

\section{Benefits of Cold Application in Reducing Pain in Musculoskeletal Disorders}

Cold application is a vasoconstriction and is utilized just after damage happens and can proceed for as long as 48 hours. Cold application should just be applied for 10-20 minutes one after another. It may very well be expelled for 10 minutes and afterward reapplied once more. The most widely recognized for cold application is ice and ought not be applied directly to the skin, but the ice has to be enveloped by towel. ${ }^{7}$ Numerous investigations
1,2Department of Medical Surgical Nursing, Kasturba Gandhi Nursing
College, Sri Balaji Vidyapeeth Deemed University, Puducherry, India

Corresponding Author: Malarmathi M, Department of Medical Surgical Nursing, Kasturba Gandhi Nursing College, Sri Balaji Vidyapeeth Deemed University, Puducherry, India, Phone: +91 7339088532, e-mail: malarmathi870@gmail.com

How to cite this article: Malarmathi M, Renuka K. Electrical Oxygencompressed Cold Application Cuff on Pain among Patients with Musculoskeletal Disorders. Pon J Nurs 2019;12(3):78-79.

Source of support: Nil

Conflict of interest: None

have exhibited that quick utilization of cold application is useful in the intense period of aggravation, as it decreases neighborhood tissue digestion and elevates vasoconstriction to adjust the incendiary reaction. The advantages of cold application are not restricted to the postoperative setting, as studies recommend clinical upgrades following the expansion of irregular cold treatment to the recovery of routine musculoskeletal injuries. ${ }^{8,9}$ According to Bleakley et al., discontinuous cold application brought about better pain management during the beginning period of restoration following lower leg sprains. ${ }^{10}$

\section{Mechanism of Oxygen-compressed Cold Application Cuff}

The researcher's idea was to reduce pain outcome of musculoskeletal disorders. This was achieved by inventing a new device called oxygen-compressed cold application cuff. The device functions by using a $12 \mathrm{~V}$ electric power (i.e., the direct current used by a pen torch battery). The device consisted of cylinder-shaped plastic container prefilled with cold water and ice cubes maintained at an average temperature of $15^{\circ} \mathrm{C}$. The cold water of $350-450 \mathrm{~mL}$ was maintained 
in the plastic container that also had oxygen with electrical motor power. For the working of the device, first the button for cold water should be switched on followed by switching on the second button for oxygen compression. The plastic tube carries the oxygen and cold water into the cuff placed in the skin, thereby reducing the musculoskeletal pain. To assess the skin temperature and to prevent complication under the skin, a thermosensor was used to detect the skin temperature. Applied over the area for 20-30 minutes and reapplied if the subject complaints of pain. After that switch off the button. Oxygen-compressed cold application cuff is applied over the pain site for reduction in pain among patients with musculoskeletal disorders.

\section{Rationale for Oxygen-compressed Cold Application}

Cold application involves deep application of cold. It works by the mechanism of preventing the perception of pain by decreasing the conduction time of the sensory nociceptors in the brain providing a mechanical effect of vasoconstriction. It provides relief from sore muscles and joints, while the oxygen-compressed cold application reduces swelling and inflammation. Oxygen-compressed cold application cuff is designed for specific body parts such as the ankle, elbow, foot, back, knee, and shoulder. They combine the benefits of cold therapy with the added advantage of compression therapy through the use of a simple pump. Some body parts, such as the ankle, can be difficult to ice because of their shape. The oxygencompressed cold application treatment to injured ankles can be achieved by creating a custom fit for the ankle. One system that can provide cold therapy relief to different body parts. It delivers localized cold water with oxygen compression with the help of cuff by cold water to the desired body part such as your knee, shoulders, or back, resulting in better painrelief. ${ }^{7}$

\section{References}

1. James $\mathrm{SL}$, Abate $\mathrm{D}$, Abate $\mathrm{KH}$, Abay SM, Abbafati C, Abbasi N, et al. Global, regional, and national incidence, prevalence, and years lived with disability for 354 diseases and injuries for 195 countries and territories, 1990-2017: a systematic analysis for the global burden of disease study 2017. Lancet 2018;392(10159):1789-1858. DOI: 10.1016/ S0140-6736(18)32279-7.

2. Storheim K, Zwart JA. Musculoskeletal disorders and the global burden of disease study. Ann Rheum Dis 2014;73(6):949-950. DOI: 10.1136/annrheumdis-2014-205327.

3. Vos T, Flaxman AD, Naghavi M, Lozano R, Michaud C, Ezzati M, et al. Years lived with disability (YLDs) for 1160 sequelae of 289 diseases and injuries 1990-2010: a systematic analysis for the global burden of disease study 2010. The Lancet 2012;380(9859):2163-2196. DOI: 10.1016/S0140-6736(12)61729-2.

4. Sharma P, Bihari V, Agarwal SK, Verma V, Kesavachandran CN, Pangtey $\mathrm{BS}$, et al. Groundwater contaminated with hexavalent chromium [Cr(VI)]: a health survey and clinical examination of community inhabitants (Kanpur, India). PLoS ONE 2012;7(10):e47877. DOI: 10.1371/ journal.pone.0047877.

5. Nermin Y. Musculoskeletal disorders (Msds) and dental practice. part 1. General information-terminology, aetiology, work-relatedness, magnitude of the problem, and prevention. Int Dent J 2006;56(6):3 59-366. DOI: 10.1111/j.1875-595x.2006.tb00342.x.

6. Brennan-Olsen SL, Cook S, Leech MT, Bowe SJ, Kowal P, Naidoo N, et al. Prevalence of arthritis according to age, sex and socioeconomic status in six low and middle income countries: analysis of data from the world health organization study on global ageing and adult health (SAGE) wave 1. BMC Musculosk Disord 2017;18(1):271.

7. Malanga GA, Yan N, Stark J. Mechanisms and efficacy of heat and cold therapies for musculoskeletal injury. Postgrad Med 2015;127(1):57-65. DOI: 10.1080/00325481.2015.992719.

8. Schaser KD, Disch AV, Stover JF, Lauffler A, Bail HJ, Mittlmeier T. Prolonged superficial local cryotherapy attenuates microcirculatory impairment, regional inflammation, and muscle necrosis after closed soft tissue injury in rats. Am J Sports Med 2007;35(1):93-102. DOI: $10.1177 / 0363546506294569$.

9. Schroder D, Passler HH. Combination of cold and compression after knee surgery: a prospective randomized study. Knee Surg Sports Traumatol Arthrosc 1994;2(3):158-165.

10. Bleakley CM, McDonough SM, MacAuley DC. Cryotherapy for acute ankle sprains: a randomized controlled study of two different icing protocols. Br J Sports Med 2006;40(8):700-705. DOI: 10.1136/ bjsm.2006.025932. 